\title{
Detection of alpha and betacoronaviruses in multiple Iberian bat species
}

\author{
Ana Falcón · Sonia Vázquez-Morón • Inmaculada Casas • Carolina Aznar • \\ Guillermo Ruiz • Francisco Pozo • Pilar Perez-Breña • Javier Juste • \\ Carlos Ibáñez · Inazio Garin · Joxerra Aihartza · Juan E. Echevarría
}

Received: 2 February 2011 / Accepted: 20 June 2011 / Published online: 16 July 2011

(C) The Author(s) 2011. This article is published with open access at Springerlink.com

\begin{abstract}
Bat coronaviruses $(\mathrm{CoV})$ are putative precursors of the severe acute respiratory syndrome (SARS) CoV and other $\mathrm{CoV}$ that crossed the species barrier from zoonotic reservoirs into the human population. To determine the presence and distribution of $\mathrm{CoV}$ in Iberian bats, 576 individuals of 26 different bat species were captured in 13 locations in Spain. We report for the first time the presence of 14 coronaviruses in 9 Iberian bat species. Phylogenetic analysis of a conserved $\mathrm{CoV}$ genome region (RdRp gene) shows a wide diversity and distribution of alpha and betacoronavirus in Spain. Interestingly, although some of these viruses are related to other European BatCoV, or to Asian $\mathrm{CoV}$, some of the viruses found in Spain cluster in new groups of $\alpha$ and $\beta \mathrm{CoV}$.
\end{abstract}

GenBank accession numbers: Partial sequences of RdRp gene of bat coronaviruses obtained in this study were deposited in GenBank under the accession numbers HQ184049 to HQ184062.

A. Falcón · S. Vázquez-Morón · I. Casas · C. Aznar · G. Ruiz ·

F. Pozo $\cdot$ P. Perez-Breña $\cdot$ J. E. Echevarría

Centro Nacional de Microbiología, Instituto de Salud Carlos III,

Madrid, Spain

A. Falcón $(\bowtie)$

Centro Nacional de Biotecnología, CSIC, Darwin 3,

Campus Cantoblanco, 28049 Madrid, Spain

e-mail: afalcon@cnb.csic.es

J. Juste $\cdot$ C. Ibáñez

Estación Biológica de Doñana, CSIC, Seville, Andalusia, Spain

I. Garin · J. Aihartza

Department of Zoology and Animal Cell Biology,

University of the Basque Country (UPV/EHU),

Leioa, The Basque Country, Spain
The emergence of infectious diseases is a major threat to global public health in this century (WHO, World Health Report http://www.who.int/whr/previous/en/index.html) and many of these new infectious human diseases are caused by viruses emerging from wildlife. In the last 50 years, more than 30 new infectious human diseases have been identified (WHO, World Health Report http://www.who.int/whr/previous/en/index.html) including the Severe Acute Respiratory Syndrome (SARS). The aetiological agent of this disease was identified as a previously unknown coronavirus (SARS-CoV) [1] and BatCoV are putative precursors of SARS-CoV [2]. The outbreak of SARS-CoV and subsequent identification of two additional human coronaviruses (HCoV-NL63[3] and HCoV-HKU1 [4]) has drawn human and animal health attention to Coronavirinae subfamily, that includes three genera, Alphacoronavirus ( $\alpha \mathrm{CoV})$, Betacoronavirus $(\beta \mathrm{CoV})$ and Gammacoronavirus $(\gamma \mathrm{CoV})$, replacing the classical groups 1, 2 and 3 [5] (http://talk.ictvonline.org/ media/g/vertebrate-2008/default.aspx).

The relevance and possible re-emergence of the pandemic SARS-CoV and other emerging viruses of zoonotic origin have activated surveillance systems of hazard agents in wild animals, including bats. As a result of these studies, bats have been described as putative reservoirs for some emerging viruses affecting humans [6]. BatCoV are putative precursors of $\mathrm{CoV}$ affecting humans and mammals [7, 8], including SARS-CoV [2] and other CoV that crossed the species barrier from zoonotic reservoirs into the human population [9]. In fact, association of some of these $\mathrm{CoV}$ to certain bat species has been suggested $[10,11]$, reinforcing the notion that there may be a relationship between some BatCoV and their hosts. Nowadays the presence of $\mathrm{CoV}$ has been shown in bats in China [12,13], North and South America [14-17], Africa [18] and a number of regions in 
Europe [11, 19-21] but not the Iberian Peninsula (Spain and Portugal), which is a bridge for European and African bat populations [22]. Thus, surveillance of wildlife reservoirs of putative zoonotic $\mathrm{CoV}$ is necessary, not only to unveil the ecology of these viruses, but also to permit early detection of viruses that might pose a threat to human health.

To determine the presence and distribution of putative zoonotic $\mathrm{CoV}$ in Iberian bats, 576 individuals from 26 bat species were captured and sampled in 13 different locations throughout Spain during 2004-2007 (Fig. 1). These samples were collected in the context of bat rhabdoviruses and lyssaviruses Surveillance Program in Spain. Most of the sampled bat species are also distributed across Europe, but Eptesicus isabellinus is a meridional serotine bat restricted to North Africa and the Iberian Peninsula [23], and Myotis escalerai is endemic in the Iberian Peninsula. Bats were caught with mist nets mainly as they left diurnal roost and by hand with polyethylene butterfly nets within roosts. Oro-pharyngeal swabs $(n=390)$ between 2004 and 2007 as well as faecal samples from individual bats $(\mathrm{n}=216)$ in 2007 were taken before bats were released (Table 1).

Oro-pharyngeal swabs collected between 2004 and 2006 were preserved in $1 \mathrm{ml}$ of lysis buffer (4 M GuSCN (Sigma), OS\% N-lauroyl Sarcosine (Sigma), $1 \mathrm{mM}$ dithiothreitol (DTT, Sigma), $25 \mathrm{mM}$ Sodium Citrate and $20 \mathrm{pg} /$ tube Glycogen (Boehringer Mannheim). Oro-pharyngeal swabs and faeces collected in 2007 were preserved in both $1 \mathrm{ml}$ of lysis buffer and $1 \mathrm{ml}$ of viral transport medium (VTM) (Eagle's minimal essential medium (EMEM) supplemented with $10 \mathrm{UI} / \mathrm{ml}$ of penicillin, $10 \mu \mathrm{g} / \mathrm{ml}$ of streptomycin, $160 \mu \mathrm{g} / \mathrm{ml}$ of gentamicin, $50 \mathrm{UI} / \mathrm{ml}$ of mycostatin and $1 \%$ of

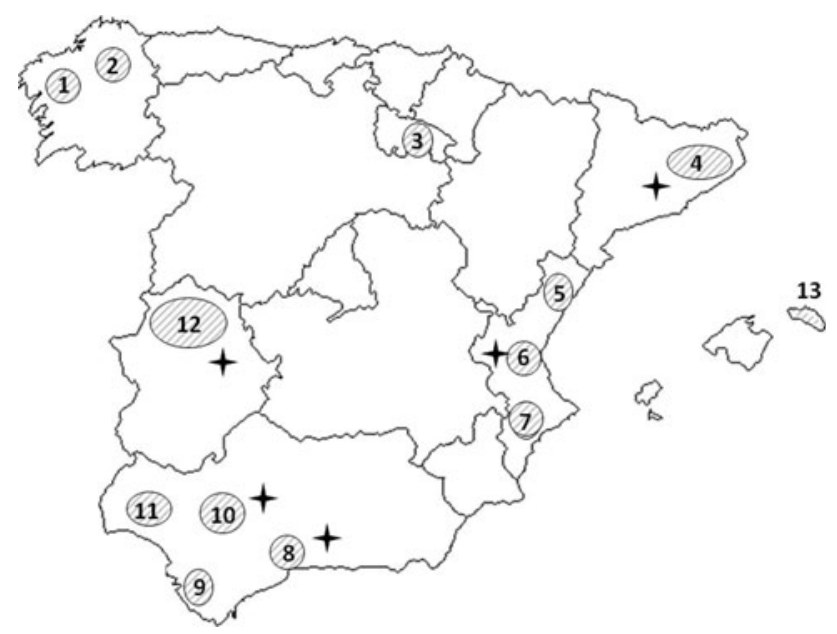

Fig. 1 Geographical location of bat capture sites in Spain. 1: A Coruña, 2: Lugo, 3: La Rioja, 4: Gerona, 5: Castellón, 6: Valencia, 7: Alicante, 8: Málaga, 9: Cádiz, 10: Sevilla, 11: Huelva, 12: Cáceres, 13: Menorca. The stars show the locations where positive samples were found bovine serum albumin). All samples were frozen at $-80^{\circ} \mathrm{C}$ before sending them to the Rabies Reference Laboratory at the Centro Nacional de Microbiología, ISCIII in Madrid. Faecal samples were clarified by centrifugation. Total nucleic acid was extracted from a $200 \mu \mathrm{l}$ aliquot of each specimen for PCR assays and the rest were stored to $-80^{\circ} \mathrm{C}$ in two different aliquots. Final pellets were always resuspended to $55 \mu$ of water.

A pan-coronavirus nested PCR was designed in the RdRp gene. A total of $5 \mu \mathrm{l}$ of extracted RNA was added to $45 \mu \mathrm{l}$ of reaction mixture of OneStep RT-PCR kit (QIAGEN, Valencia, CA, USA) containing $200 \mu \mathrm{M}$ dNTPs and $60 \mathrm{pmol}$ of generic CoV-specific degenerated primers (forward 5'-CARATGAATYTIAARTAYGC- $3^{\prime}$ and reverse $5^{\prime}$-TGYTGWGARCAAAAYTCRTG-3') and following manufacturer indications. Amplifications were carried out into thin-walled reaction tubes (Sorenson, BioScience, UT) in a PTC-200 (Peltier Thermal Cycler, MJ Research, Watertown, MA). Nested PCR amplifications were performed using $2 \mu \mathrm{l}$ of first amplification product and $48 \mu \mathrm{l}$ of reaction mixture containing $60 \mathrm{mM}$ Tris- $\mathrm{HCl}$ (pH 8.5), $15 \mathrm{mM}(\mathrm{NH} 4)_{2} \mathrm{SO}_{4}, 200 \mu \mathrm{M}$ dNTPs (Amersham Pharmacia Biotech, Piscataway, $\mathrm{NJ}), 3 \mathrm{mM} \mathrm{MgCl}_{2}$, 35 pmol of generic $\mathrm{CoV}$-specific degenerated primers (forward 5'-ATGGGWTGGGAYTAYCCIAARTG-3'and reverse $5^{\prime}$-ACRTTRTTYTGRWARTA-3') and $1.25 \mathrm{U}$ AmpliTaq DNA Polymerase (Perkin-Elmer Cetus, Norwalk). Amplification product size of $512 \mathrm{nt}$ was visualized by agarose gel electrophoresis and sequenced directly in both directions using an automated ABI PRISM 377 model sequencer. For phylogeny reconstruction, consensus sequences were aligned together with others obtained from public genomic databases using the program CLUSTAL X (version 1.83) (Table 2). A Bayesian phylogenetic inference was obtained using Mr Bayes version 3.1 [24] with random starting trees without constraints. For the analyses GTR substitution model, gamma estimation and two simultaneous runs of $10^{7}$ generations were done, each with four Markov chains, and the trees were sampled every 100 generations. Amino acid identity was calculated with MEGA 4 using the pairwise deletion option. The alignment comprised the same $396 \mathrm{bp}$ of the RdRp gene used for the phylogenetic reconstruction.

A total of 26 out of the 30 known bat species known for Iberian Peninsula were screened for $\mathrm{CoV}$ and 14 samples taken from 9 bat species, all included in the family Vespertilionidae, were positive for CoV RNA (Tables 1 and 2). Twelve of them were found within faecal samples (5.5\%) of 7 different bat species in 6 locations and two were obtained in oral samples $(0.5 \%)$ of 2 other different species in the same location (Table 1). In view of these results, it is not surprising that the presence of CoV RNA is significantly more frequent in faeces than in oral cavity 
Table 1 Results of detection of CoV RNA in faecal or oral samples of bats collected in Spain

\begin{tabular}{|c|c|c|c|c|}
\hline Bat Species & $\begin{array}{l}\text { Faecal samples } \\
\text { positive/no. tested }\end{array}$ & $\begin{array}{l}\text { Oral samples } \\
\text { positive/no. tested }\end{array}$ & Location & Genus \\
\hline Barbastella barbastellus & $0 / 4$ & $0 / 2$ & 3,4 & \\
\hline Eptesicus isabellinus & $1 / 8$ & NA & $10^{\mathrm{a}}$ & $\beta$ \\
\hline Eptesicus serotinus & $0 / 7$ & NA & 1,12 & \\
\hline Hypsugo savii & $2 / 26$ & $0 / 10$ & $2,4^{\mathrm{a}}, 12^{\mathrm{a}, \mathrm{b}}$ & $\alpha, \beta$ \\
\hline Miniopterus schreibersii & $0 / 2$ & $1 / 71$ & $2,5,6^{\mathrm{a}}, 7,8,9,12,13$ & $\alpha$ \\
\hline Myotis alcathoe & $0 / 1$ & NA & 3 & \\
\hline Myotis bechsteinii & $0 / 2$ & $0 / 3$ & 4,8 & \\
\hline Myotis blythii & NA & $1 / 11$ & $6^{\mathrm{a}}, 7,12$ & $\alpha$ \\
\hline Myotis capaccinii & NA & $0 / 14$ & $5,6,13$ & \\
\hline Myotis daubentonii & $1 / 39$ & $0 / 52$ & $2,3,8^{\mathrm{a}}, 11,12$ & $\alpha$ \\
\hline Myotis emarginatus & NA & $0 / 2$ & 8,12 & \\
\hline Myotis escalerai & NA & $0 / 15$ & 11,7 & \\
\hline Myotis myotis & $1 / 1$ & $0 / 17$ & $6,7,8^{\mathrm{a}}, 12$ & $\alpha$ \\
\hline Myotis mystacinus & $0 / 5$ & NA & 2,3 & \\
\hline Myotis nattereri & $0 / 3$ & $0 / 3$ & 4 & \\
\hline Nyctalus lasiopterus & $5 / 37$ & $0 / 137$ & $3,8^{\mathrm{a}, \mathrm{b}}, 9,10,11$ & $\alpha$ \\
\hline Nyctalus leisleri & $0 / 23$ & $0 / 11$ & $2,3,4,8$ & \\
\hline Pipistrellus kuhlii & $1 / 4$ & $0 / 6$ & $8,12^{\mathrm{a}}$ & $\alpha$ \\
\hline Pipistrellus pipistrellus & $0 / 3$ & $0 / 1$ & 3,12 & \\
\hline Pipistrellus pygmaeus & NA & $0 / 1$ & 12 & \\
\hline Pipistrellus sp. & $1 / 29$ & $0 / 5$ & $1,2,4,8,12^{\mathrm{a}, \mathrm{b}}$ & $\alpha$ \\
\hline Plecotus auritus & $0 / 7$ & NA & $1,3,4$ & \\
\hline Plecotus austriacus & $0 / 7$ & $0 / 10$ & $4,11,12$ & \\
\hline Rhinolophus euryale & NA & $0 / 13$ & $6,7,12$ & \\
\hline Rhinolophus ferrumequinum & $0 / 3$ & $0 / 5$ & $4,8,12$ & \\
\hline Rhinolophus hipposideros & $0 / 4$ & NA & 4,12 & \\
\hline Rhinolophus mehelyi & NA & $0 / 1$ & 12 & \\
\hline Total & $12 / 216$ & $2 / 390$ & $1,2,3,4,5,6,7,8,9,10,11,12,13$ & $\alpha, \beta$ \\
\hline
\end{tabular}

NA no samples available

${ }^{a}$ Locations where positives samples were found

b These samples were collected in different localities than other positive samples with the same number location

$(\mathrm{p}<0.0001$, FISHER EXACT TEST). It is of interest that none of the viruses has been found in oropharingeal and faecal samples of the same individual, when both samples were available. This fact may indicate either that the infection was at different stage in the different individuals at the time of sampling or that replication of virus may take place independently in the intestinal and respiratory tracts [25]. Most of the CoV RNA sequences found in faecal samples $(83 \%)$ correspond to $\alpha \mathrm{CoV}$, the remaining two belonging to $\beta \mathrm{CoV}$. All $\mathrm{CoV}$ RNAs from oral samples $(100 \%)$ were found to contain viral RNA sequences corresponding to $\alpha \mathrm{CoV}$. In agreement with all previous studies [7], none of the coronavirus detected in Spanish bats belong to group $\gamma$.

The phylogenetic analysis of Spanish BatCoV was performed using 396nt out of the 512 nt RT-PCR amplified fragments. 116nt fragment information was lost to allowed us include more sequences from other European countries and other continents deposited in GenBanK to perform a meaningful analysis. This small part of the RdRp gene has been previously used, and sufficiently represents the full gene information, for phylogenetic analysis of BatCoV [11, 14, 20]

The phylogenetic reconstruction showed 6 different lineages of Spanish BatCoV (Fig. 2). BatCoV A and B were closely related to other $\alpha$ BatCoV found in China [12], although they appeared to display certain genetic differentiation (Fig. 2). Myotis daubentonii-associated $\mathrm{CoV} \mathrm{H}$, and Pipistrellus-associated $\mathrm{CoV} \mathrm{K}$, clustered respectively with lineages 4 and 3 of $\alpha \mathrm{CoV}$ previously described in Germany and are hosted by the same bat species or genera [11] (Fig. 2). BatCoV L was closely 
Table 2 Data of interest related to the 91 coronavirus sequences used for the generation of the phylogenetic tree

\begin{tabular}{|c|c|c|c|c|}
\hline Access no & Host species & Country & Genus & Cluster \\
\hline DQ249221 & Bat & China & $\beta$ & HKU5 \\
\hline DQ249219 & Bat & China & $\beta$ & HKU5 \\
\hline DQ249218 & Pipistrellus sp. & China & $\beta$ & HKU5 \\
\hline DQ648809 & Bat & China & $\beta$ & \\
\hline DQ648807 & Bat & China & $\beta$ & \\
\hline DQ249217 & Pipistrellus sp. & China & $\beta$ & HKU5 \\
\hline DQ648819 & Bat & China & $\beta$ & \\
\hline DQ249215 & Tylonycteris & China & $\beta$ & HKU4 \\
\hline DQ249214 & Tylonycteris & China & $\beta$ & HKU4 \\
\hline DQ074652 & Tylonycteris & China & $\beta$ & HKU4 \\
\hline DQ249216 & Tylonycteris & China & $\beta$ & HKU4 \\
\hline DQ648803 & Bat & China & $\beta$ & \\
\hline HQ184059 & Hypsugo savii & Spain & $\beta$ & \\
\hline HQ184062 & Eptesicus isabellinus & Spain & $\beta$ & \\
\hline GQ404795 & Rhinolophus hipposideros & Slovenia & $\beta$ & \\
\hline GQ404796 & Rhinolophus hipposideros & Slovenia & $\beta$ & \\
\hline GQ404797 & Rhinolophus hipposideros & Slovenia & $\beta$ & \\
\hline DQ022305 & Rhinolophus sinicus & China & $\beta$ & \\
\hline NC_009696 & Rhinolophus macrotis & & $\beta$ & \\
\hline NC_004718 & Human & & $\beta$ & \\
\hline NC_009021 & Rousettus leschenaulti & China & $\beta$ & HKU9 \\
\hline NC_006577 & Human & & $\beta$ & \\
\hline NC_006852 & Mouse & & $\beta$ & \\
\hline NC_007732 & Pig & & $\beta$ & \\
\hline NC_005147 & Human & & $\beta$ & \\
\hline EF544563 & Myotis occultus & USA & $\alpha$ & \\
\hline EF544565 & Myotis occultus & USA & $\alpha$ & \\
\hline HQ184049 & Miniopterus schreibersii & Spain & $\alpha$ & \\
\hline HQ184050 & Myotis blythii & Spain & $\alpha$ & \\
\hline DQ648838 & Bat & China & $\alpha$ & \\
\hline DQ648855 & Rhinolophus ferrumequinum & China & $\alpha$ & \\
\hline DQ648854 & Rhinolophus ferrumequinum & China & $\alpha$ & \\
\hline NC_003436 & Pig & & $\alpha$ & \\
\hline EU375862 & Myotis dasycneme & Germany & $\alpha$ & \\
\hline EU375859 & Myotis dasycneme & Germany & $\alpha$ & \\
\hline EU375858 & Myotis dasycneme & Germany & $\alpha$ & \\
\hline EU375855 & Myotis dasycneme & Germany & $\alpha$ & \\
\hline EU375863 & Myotis dasycneme & Germany & $\alpha$ & \\
\hline EU375861 & Myotis dasycneme & Germany & $\alpha$ & \\
\hline EU375856 & Myotis dasycneme & Germany & $\alpha$ & \\
\hline EU375854 & Myotis dasycneme & Germany & $\alpha$ & \\
\hline EU375857 & Myotis dasycneme & Germany & $\alpha$ & \\
\hline EU375865 & Myotis bechsteinii & Germany & $\alpha$ & \\
\hline EU375853 & Myotis bechsteinii & Germany & $\alpha$ & \\
\hline EU375860 & Myotis bechsteinii & Germany & $\alpha$ & \\
\hline EU375869 & Pipistrellus nathusii & Germany & $\alpha$ & \\
\hline EU375864 & Pipistrellus nathusii & Germany & $\alpha$ & \\
\hline EU375870 & Pipistrellus pygmaeus & Germany & $\alpha$ & \\
\hline
\end{tabular}


Table 2 continued

\begin{tabular}{|c|c|c|c|c|}
\hline Access no & Host species & Country & Genus & Cluster \\
\hline EU375868 & Pipistrellus pygmaeus & Germany & $\alpha$ & \\
\hline EU375867 & Pipistrellus pygmaeus & Germany & $\alpha$ & \\
\hline HQ184060 & Pipistrellus sp. & Spain & $\alpha$ & \\
\hline DQ648822 & Bat & China & $\alpha$ & \\
\hline DQ648821 & Bat & China & $\alpha$ & \\
\hline DQ648824 & Bat & China & $\alpha$ & \\
\hline DQ648823 & Bat & China & $\alpha$ & \\
\hline EU375875 & Myotis daubentonii & Germany & $\alpha$ & \\
\hline EU375873 & Myotis daubentonii & Germany & $\alpha$ & \\
\hline EU375874 & Myotis daubentonii & Germany & $\alpha$ & \\
\hline EU375872 & Myotis daubentonii & Germany & $\alpha$ & \\
\hline EU375866 & Myotis daubentonii & Germany & $\alpha$ & \\
\hline HQ184056 & Myotis daubentonii & Spain & $\alpha$ & \\
\hline EU375871 & Myotis daubentonii & Germany & $\alpha$ & \\
\hline DQ648833 & Myotis ricketti & China & $\alpha$ & \\
\hline DQ249224 & Myotis ricketti & China & $\alpha$ & HKU6 \\
\hline DQ648837 & Myotis ricketti & China & $\alpha$ & \\
\hline DQ249235 & Rhinolophus sinicus & China & $\alpha$ & HKU2 \\
\hline DQ249213 & Rhinolophus sinicus & China & $\alpha$ & HKU2 \\
\hline DQ648840 & Bat & China & $\alpha$ & \\
\hline DQ249228 & Miniopterus sp. & China & $\alpha$ & HKU8 \\
\hline EU834954 & Miniopterus australis & Australia & $\alpha$ & \\
\hline EU834952 & Miniopterus australis & Australia & $\alpha$ & \\
\hline EU834955 & Miniopterus schreibersii & Australia & $\alpha$ & \\
\hline EU834953 & Rhinolophus megaphyllus & Australia & $\alpha$ & \\
\hline DQ648835 & Miniopterus schreibersii & China & $\alpha$ & \\
\hline DQ648796 & Bat & China & $\alpha$ & \\
\hline DQ648797 & Bat & China & $\alpha$ & \\
\hline DQ249226 & Miniopterus magnater & China & $\alpha$ & HKU7 \\
\hline HQ184061 & Hypsugo savii & Spain & $\alpha$ & \\
\hline HQ184051 & Nyctalus lasiopterus & Spain & $\alpha$ & \\
\hline HQ184054 & Nyctalus lasiopterus & Spain & $\alpha$ & \\
\hline HQ184053 & Nyctalus lasiopterus & Spain & $\alpha$ & \\
\hline HQ184052 & Nyctalus lasiopterus & Spain & $\alpha$ & \\
\hline HQ184055 & Nyctalus lasiopterus & Spain & $\alpha$ & \\
\hline HQ184057 & Myotis myotis & Spain & $\alpha$ & \\
\hline HQ184058 & Pipistrellus kuhlii & Spain & $\alpha$ & \\
\hline EU834951 & Myotis macropus & Australia & $\alpha$ & \\
\hline NC_002645 & Human & & $\alpha$ & \\
\hline NC_005831 & Human & & $\alpha$ & \\
\hline AY994055 & Cat & & $\alpha$ & \\
\hline NC_002306 & Pig & & $\alpha$ & \\
\hline NC_001451 & Chicken & & $\gamma$ & \\
\hline
\end{tabular}




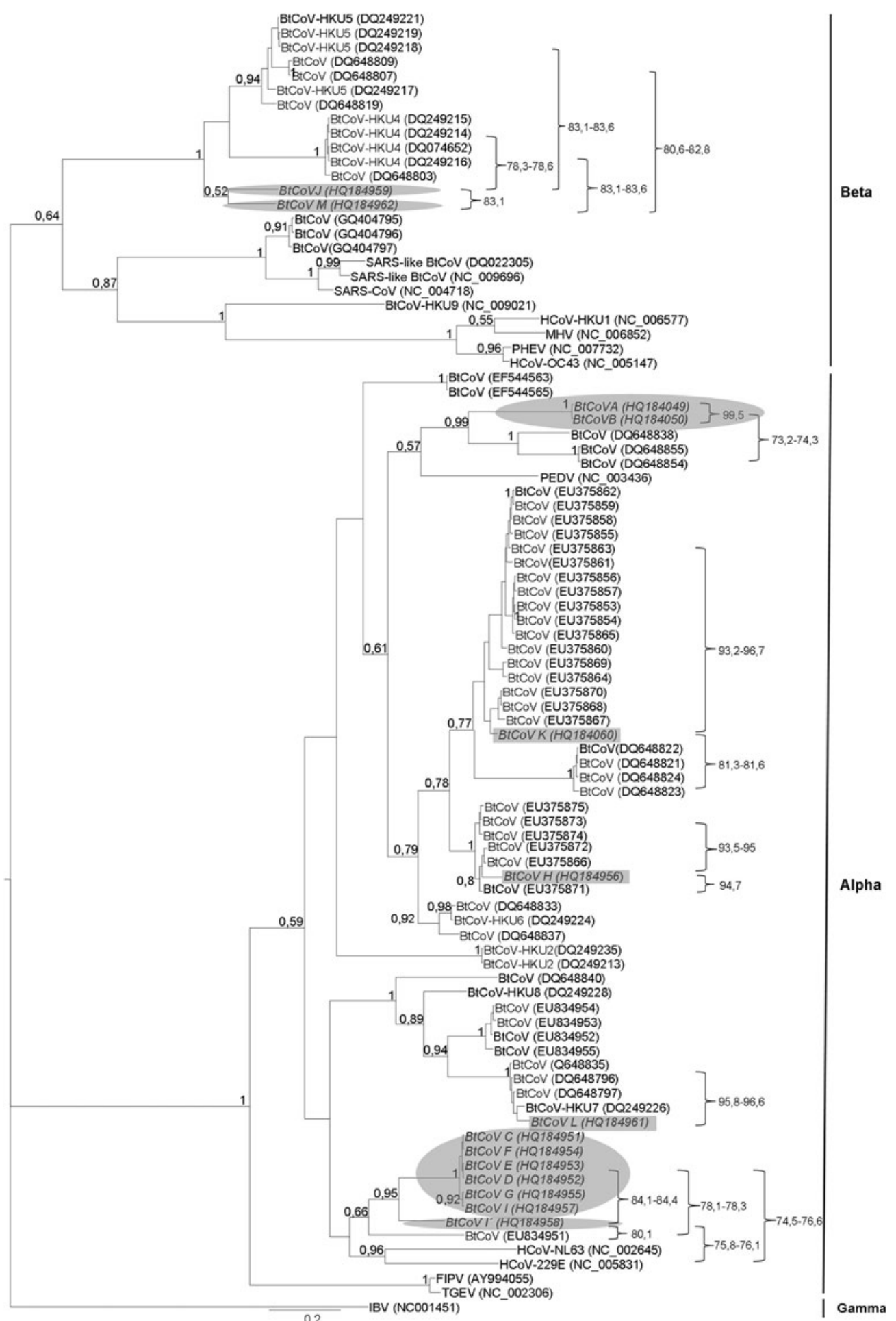

Fig. 2 CoV phylogenetic reconstruction based on 396 bp of the RdRp gene including 14 Spanish CoV from different bat species and 77 alpha, beta and gammacoronaviruses obtained from GenBank. Accession numbers are shown in brackets. BatCoV detected in Spain are highlighted in italics. For the analyses GTR substitution model, gamma estimation and two simultaneous runs of $10^{7}$ generations were done, each with four Markov chains, and the trees were sampled every 100 generations. First $25 \%$ trees were excluded as burn-in from the analysis. Significant posterior probabilities are indicated. Complementary information about sequences used in this phylogenetic reconstruction are shown in Table 2. Positive samples described in this work are shown in shaded rectangles and ovals. The new alpha and betacoronavirus groups described in this work are shown in shaded ovals. Amino acid identity was calculated with MEGA 4 using the pairwise deletion option. The alignment comprised the same 396 bp of the RdRp gene used for the phylogenetic reconstruction. Amino acid identities across 132 amino acids are indicated next to the brackets that links every Spanish BatCoV to the phylogenetic neighbours 
related to cluster HKU7 described in China [10]. BatCoV $\mathrm{C}, \mathrm{D}, \mathrm{E}, \mathrm{F}, \mathrm{G}$ and $\mathrm{I}$ belonged to the same lineage and showed an intriguing new independent cluster (significant posterior probability $=0.95$ ) including BatCoV I' (Fig. 2). In addition, BatCoV $\mathrm{J}$ and $\mathrm{M}$ were genetically related to $\beta$ $\mathrm{CoV}$, although they did not really associate with any of their previously described linages. Sequences corresponding to two different groups of $\mathrm{CoV}$ were found in the same bat species (Hypsugo savii) as it was also found for other bat species elsewhere [12]. Spanish BatCoV described here were also classified calculating amino acid distances of these viruses from phylogenetic neighbours and related reference species [21]. Amino acid distance criteria recently described for separating RdRp grouping units (RGU) were adopted [21]. Interestingly, the amino acid distance criteria $(>4.8 \%$ for alphacoronavirus and $>6.3 \%$ for betacoronavirus) reinforced the presence of the new group of alphacoronaviruses mentioned above including Spanish BatCoV C, D, E, F, G and I; and additionally showed four new tentative groups (Fig. 2). BatCoV A and $\mathrm{B}$ were included in a new alphacoronavirus group and BatCoV I' constituted another independent alphacoronavirus group. BatCoV J, and $\mathrm{M}$ represented two new betacoronavirus groups and $\mathrm{BatCoV} \mathrm{H}, \mathrm{K}$ and $\mathrm{L}$ remained as part of several established species (Fig. 2).

It has been previously suggested that some $\mathrm{CoV}$ associate to certain bat species $[10,11]$. However, we found that different bat species from the same colony or location harbour $\mathrm{CoV}$ of the same genetic lineage (BatCoV A and $\mathrm{B} ; \mathrm{G}$ and I), indicating a greater diversity and higher complexity than previously described for the ecology of BatCoV. Similar exceptions were found in China and South America [12, 16, 26] and could also be observed with Australian BatCoV (Fig. 2 and Table 2).

In conclusion, previous studies showed the presence of $\mathrm{BatCoV}$ in Europe. However, to our knowledge, this is the first report describing the presence of CoV RNA in Iberian bat species. Phylogenetic data indicate high diversity, wide distribution and complex ecology of $\mathrm{CoV}$ in bats captured in diverse Spanish locations. The sequences reported herein provide new insights into the diversity of coronaviruses and describe new phylogenetic linages that appear to diverge from all genotypes previously detected in other European locations. Future studies should clarify whether such apparently high diversity reflects the bio-geographical peculiarities of the Iberian Peninsula or not. This study contributes with a new dataset to the global surveillance of emerging BatCoV with pathogenic potential in humans. Our data reinforce the notion that the ecology and transmission of $\mathrm{CoV}$ in bat reservoirs is far from being completely understood and that more studies will be necessary to evaluate the magnitude of the potential threat that these viruses pose to human health.
Acknowledgments We gratefully thank S. Perlman and P. Woo for providing MHV RNA and HCoV-HKU1 RT-PCR products respectively, as controls for pancoronavirus PCR development. We also thank L. Enjuanes for scientific discussions and P. Gastaminza for critical comments on the manuscript. We are grateful to David García, Ana Popa, Grupo Drosera, Museu de Granollers and everyone who participated in the collection of field samples and the Genomic Unit of the National Center of Microbiology for analyzing the genomic sequences. This work was supported by a Spanish Ministry of Science and Innovation grant (Projects SAF2006-12784-C02-01 and SAF2006-12784-C02-02) and a grant from the Basque Government (ref. IT301-10)

Conflict of interest The authors declare no conflict of interest.

Open Access This article is distributed under the terms of the Creative Commons Attribution Noncommercial License which permits any noncommercial use, distribution, and reproduction in any medium, provided the original author(s) and source are credited.

\section{References}

1. Drosten C, Günther S, Preiser W, van der Werf S et al (2003) Identification of a novel coronavirus in patients with severe acute respiratory syndrome. N Engl J Med 348:1967-1976

2. Li W, Shi Z, Yu M, Ren W, Smith C, Epstein JH, Wang H et al (2005) Bats are natural reservoirs of SARS-like coronaviruses. Science 310:676-679

3. van der Hoek L, Pyrc K, Jebbink MF, Vermeulen-Oost W, Berkhout RJ, Wolthers KC, Wertheim-van Dillen PM, Kaandorp J, Spaargaren J, Berkhout B (2004) Identification of a new human coronavirus. Nat Med 10:368-373

4. Woo PC, Lau SK, Chu CM, Chan KH, Tsoi HW, Huang Y, Wong BH, Poon RW, Cai JJ, Luk WK, Poon LL, Wong SS, Guan Y, Peiris JS, Yuen KY (2005) Characterization and complete genome sequence of a novel coronavirus, coronavirus HKU1, from patients with pneumonia. J Virol 79:884-895

5. de Groot RJ, Ziebur J, Poon LL, Woo PC, Talbot P, Rottier PJM, Holmes KV, Baric R, Perlman S, Enjuanes L, Gorbalenya AE (2010) Taxonomic structure of the Coronaviridae. In: Fauquet CM, Mayo MA, Maniloff J, Desselberg U, King A (eds) Virus taxonomy. International committee on taxonomy of viruses. Academic Press, London

6. Calisher $\mathrm{CH}$, Childs JE, Field HE, Holmes KV, Schountz T (2006) Bats: important reservoir hosts of emerging viruses. Clin Microbiol Rev 19:531-545

7. Vijaykrishna D, Smith GJ, Zhang JX, Peiris JS, Chen H, Guan Y (2007) Evolutionary insights into the ecology of coronaviruses. J Virol 81:4012-4020

8. Woo PCY, Lau SKP, Huang Y, Yuen KY (2009) Coronavirus diversity, phylogeny and interspecies jumping. Exp Biol Med 234:1117-1127

9. Pfefferle S, Oppong S, Drexler JF, Gloza-Rausch F, Ipsen A, Seebens A, Muller MA, Annan A, Vallo P, Adu-Sarkodie Y, Kruppa TF, Drosten C (2009) Distant relatives of severe acute respiratory coronavirus and close relatives of human coronavirus $229 \mathrm{E}$ in bats, Ghana. Emerg Infect Dis 15:1377-1384

10. Woo PC, Lau SK, Li KS, Poon RW, Wong BH, Tosí HW, Yip BC, Huang Y, Chan KH, Yuen KY (2006) Molecular diversity of coronaviruses in bats. Virology 20:180-187

11. Gloza-Rausch F, Ipsen A, Seebens A, Göttsche M, Panning M, Felix Drexler J, Petersen N, Annan A, Grywna K, Müller M, Pfefferle S, Drosten C (2008) Detection and prevalence patterns 
of group I coronaviruses in bats, northern Germany. Emerg Infect Dis 14:626-631

12. Tang XC, Zhang JX, Zhang SY, Wang P, Fan XH, Li LF, Li G, Dong BQ, Liu W, Cheung CL, Xu KM, Song WJ, Vijaykrishna D, Poon LLM, Peiris JSM, Smith GJD, Chen H, Guan Y (2006) Prevalence and genetic diversity of coronavirus in bats from China. J Virol 80:7481-7490

13. Chu DK, Poon LL, Chan KH, Chen H, Guan Y, Yuen KY, Peiris JS (2006) Coronaviruses in bent-winged bats (Miniopterus spp.). J Gen Virol 87:2461-2466

14. Dominguez SR, O'Shea TJ, Oko LM, Holmes KV (2007) Detection of group 1 coronaviruses in bats in North America. Emerg Infect Dis 13:1295-1300

15. Misra V, Dumonceaux T, Dubois J, Willis C, Nadin-Davis S, Severini A, Wandeler A, Lindsay R, Artsob H (2009) Detection of polyoma and corona viruses in bats of Canada. J Gen Virol 90:2015-2022

16. Carrington CV, Foster JE, Zhu HC, Zhang JX, Smith GJ, Thompson N, Auguste AJ, Ramkissoon V, Adesiyun AA, Guan Y (2008) Detection and phylogenetic analysis of group 1 coronaviruses in South American bats. Emerg Infect Dis 14:1890-1893

17. Brandao PE, Scheffer K, Villarreal LY, Achkar S, Oliveira Rde N, Fahl Wde O, Castilho JG, Kotait I, Richtzenhain LJ (2008) A coronavirus detected in the vampire bat Desmodus rotundus. Braz J Infect Dis 12:466-468

18. Tong S, Conrardy C, Ruone S, Kuzmin IV, Guo X, Tao Y, Niezgoda M, Haynes L, Agwanda B, Breiman RF, Anderson LJ, Rupprecht CE (2009) Detection of novel SARS-like and other coronaviruses in bats from Kenya. Emerg Infect Dis 15:482-485
19. Balboni A, Palladini A, Bogliani G, Battilani M (2010) Detection of a virus related to betacoronaviruses in Italian greater horseshoe bats. Epidemiol Infect 18:1-4

20. Rihtaric D, Hostnik P, Steyer A, Grom J, Toplak I (2010) Identification of SARS-like coronaviruses in horseshoe bats (Rhinolophus hipposideros) in Slovenia. Arch Virol 155:507-514

21. Drexler JF, Gloza-Rausch F, Glende J, Corman VM, Muth D, Goettsche M, Seebens A, Niedrig M, Pfefferle S, Yordanov S, Zhelyazkov L, Hermanns U, Vallo P, Lukashev A, Müller MA, Deng H, Herrler G, Drosten C (2010) Genomic characterization of severe acute respiratory syndrome-related coronavirus in European bats and classification of coronaviruses based on partial RNA-dependent RNA polymerase gene sequences. J Virol 84:11336-11349

22. García-Mudarra JL, Ibáñez C, Juste J (2009) The Straits of Gibraltar: barrier or bridge to Ibero-Moroccan bat diversity? Biol J Linn Soc 96:434-450

23. Ibañez C, García-Mudarra JL, Ruedi M, Stadelmann B, Juste J (2006) The Iberian contribution to cryptic diversity in European bats. Acta Chiropter 8:277-297

24. Huelsenbeck JP, Ronquist F (2001) MrBayes: Bayesian inference of phylogenetic trees. Bioinformatics 17:754-755

25. Liu W, Tang F, Fontanet A, Zhan L, Zhao QM, Zhang PH, Wu XM, Zuo SQ, Baril L, Vabret A, Xin ZT, Shao YM, Yang H, Cao WC (2004) Long-term SARS coronavirus excretion from patient cohort, China. Emerg Infect Dis 10:1841-1843

26. Wang LF, Shi Z, Zhang S, Field H, Daszak P, Eaton BT (2006) Review of bats and SARS. Emerg Infect Dis 12:1834-1840 